\title{
Nursing care of vascular accident victim ischemic brain: clinical evidence
}

\begin{abstract}
Objective: To analyze the main clinical evidence available on the nursing care in the acute phase of the Accident Vascular and Nursing Care, Emergency Nursing.

Methods: A integrative vision, to search in databases: LILACS, Scielo and PubMed / Medline, whose general expression search was "Stroke" and "Nursing Care" and "Emergency Nursing". For the selection of studies, we considered the following inclusion criteria: electronic publications or printed in full, in Portuguese, from 2008 to 2015, which reflect the main evidence for patient care victimized of the Accident Vascular. Were selected nine studies, including articles, theses, manuals and protocols, which have had their quality and methodological evidence levels established as Enfermagem Protocol Based on evidence Cullum.

Results: pesquisas addresses predominantly nursing care in the prevention of risk factors for of the Accident Vascular And as control of blood pressure, obesity, lifestyle habits; and care in the rehabilitation of patients after discharge, such as physical therapy, lifestyle rehabilitation and family to the guidelines. In the emergency phase, revealed the importance of the knowledge the of neurological assessment scales and their applicability, signs and symptoms of the disease and identification of onset in order to determine the initiation of therapy within the therapeutic window 4.5 hours, addition to monitoring the signals vital, positioning the head and water and glycemic control of the individual.

Conclusion: Highlights the importance the nurse, not only in the emergency time, but also preventive care to risk factors, recurrence and rehabilitation of the individual. It is necessary to reflect on the creation of AVE units with trained professionals, as well as investment in continuing education.
\end{abstract}

Keywords: accident vascular, nursing care, emergency nursing
Volume 5 Issue 2 - 2018

\author{
Juliana Teixeira Nunes,' Edianne Silvia \\ Lustosa Cesar, ${ }^{2}$ Jairo Edielson Rodrigues \\ Barbosa de Sousa, ${ }^{3}$ Grazielle Roberta Silva \\ Freitas, ${ }^{4}$ Nisleide Vanessa Pereira das Neves ${ }^{5}$ \\ 'Enfermeira e Mestranda em Saúde, Universidade Federal do \\ Piauí, Brazil \\ ${ }^{2}$ Enfermeira Intensivista, Universidade Federal do Piauí, Brazil \\ ${ }^{3}$ Mestre em Enfermagem, Universidade Federal do Piauí, Brazil \\ ${ }^{4}$ Doutora em Enfermagem, Universidade Federal do Ceará, \\ Brazil \\ ${ }^{5}$ Acadêmica do Curso de Bacharelado em Enfermagem da \\ Faculdade IESM, Brazil
}

Correspondence: Jairo Edielson Rodrigues Barbosa de Sousa, Enfermeira e Mestranda em Saúde, Universidade Federal do Piauí, Brazil, Tel+(86)9942-8648, Email juliananunes.ufpi@gmail.com

Received: June 01, 2017| Published: March 19, 2018

\section{Introduction}

The cerebrovascular accident (CVA) is characterized by neurological symptoms that last more than 24 hours, with abrupt onset or in the form of crisis, caused by interruption of the blood supply to the encephalon, and can be formed in two ways, by obstruction of the vessels cerebral blood corresponding to ischemic stroke (ischemic stroke) occurs in $85 \%$ of cases these vessels break or corresponding to hemorrhagic stroke, prevalent in $15 \%$ of cases. ${ }^{1,2}$ The AVE has been touted since the 1960s as the leading cause of death and hospitalization in the national scene and as the third cause of death worldwide, affecting mainly the elderly population, and overcoming chronic diseases such as heart disease and cancer, constituent- if as a serious public health problem..$^{3-5}$ The impact of chronic diseases on society is growing, especially when progress to degree of disability of the affected population, reflecting the global economic scenario, noting that one third of cases of stroke reaches the economically active portion of the population. ${ }^{6}$

Brazil Ministry of Health data has shown a worrying situation in the country, since the stroke incidence rate corresponds to about 150 cases per 100,000 inhabitants and $10 \%$ of the adult population of the country $^{5}$ deaths. In addition, registered in 2008 were 200,000 deaths from the disease, which resulted in a cost for lost productivity of these patients, approximately 270 million reads for the public coffers. ${ }^{7}$
The ischemic stroke has often been named as "brain attack" in order to suggest to healthcare professionals and the public that this disease is an urgent issue for Boston Public Health lic similar to heart attack. ${ }^{8}$ The urgency is needed by the public at the time of identification of signs and symptoms, and health professionals for evaluation and rapid transport of the patient giving dry INSTANCE to appropriate treatment.

The ischemic stroke is manifested by a wide variety of neurological deficits, depending on the location and size of the lesion, causing motor loss and communication, perceptual disorders, sensory loss, cognitive impairment and psychological in the individual. Thus, it results in injury to public health due to functional loss of the active population of the country, generating large expenditures of rehabilitation treatments and permanence of chelae in most cases. ${ }^{7}$

In this sense, nursing care has a significant impact on the recovery of the patient suffering from stroke, in which many of the organ systems have often been compromised as a result of this disease. Thus, the care provided and timely interventions in the acute phase and after this can vitar and debilitating complications. ${ }^{9-11}$

Given that the time elapsed between the onsets of the symptom and therapeutic decision is critical to patient survival, it is emphasized that care run will be crucial in the rehabilitation context, reducing the 
number and severity of sequelae and even total reestablishment of the individual's capabilities. Due to the mentioned facts, it is important to highlight the main nursing care focused on last saw this neurovascular disease.

In this context, this study aimed point, the s main clinical evidence of nursing care the person victim of stroke $i$, focusing on emergency assistance to the acute phase.

\section{Methodology}

This study is an integrative review of the literature, based on the guiding question: what nursing care has been evidenced in the emergency assistance to the victim of ischemic stroke? The data search was done manually in the databases: Latin American and Caribbean Literature in Health Sciences (LILACS), Scientific Electronic Library Online (SciELO), PUBMED / Medline. The descriptors used were: "Stroke", "Nursing Care" and "Emergency Nursing", all available in the Descriptors in Health Sciences (DeCS). The general expression used search was "Stroke" and "Nursing Care" and "Emergency Nursing". Selection minute of articles was made from three filters: the first was the initial selection of studies through the general expression search and employment are the inclusion and exclusion criteria pre - established; the second filter corresponded reading the titles and abstracts of articles previously selected, excluding duplication; The third filter was performed by reading the articles selected in the previous step, refining according to quality criteria and remaining only the publications whose data presented relevance for the present research.

The criteria for selection of studies were: articles, dissertations, theses or updated technical protocols published in Brazil in Portuguese during the period 2008-2015, which should be available electronically in full or in versions of printed books, no matter Design of the research and that portrayed the cerebrovascular accident with focus on the assistance to the patient victim of ischemic stroke. We excluded from the selection the articles that, after reading the titles and the abstracts, did not fit the theme explored.

After the employment of inclusion and pre-established exclusion criteria, the final selection was analyzed when their methodological quality and established evidence levels as Enfermag of Protocol Based Cullum Evidence (2010), thus offering the best quality Customer care, based on the best evidence available. The other authors used to refer the content of this article came from the search for the primary source cited in the articles found and referenced in books and manuals used as complementary literature to search for concepts and current data of the topic addressed.

\section{Results}

After the general search using only the intersection of the search descriptors in the SCIELO databases; LILACS and PUBMED found 59 publications, which after undergoing the inclusion and exclusion criteria reduced to the selection of desired studies, selecting nine studies, including six articles, a thesis, a protocol and a manual as the final sample. The exclusion of other studies is justified by the avoidance of the focus theme of the present study and the inclusion criteria mentioned above. Table 1 shows the distribution of the studies and the variables used for analysis and selection of publications located.

Table I Distribution of studies according to variables and levels of evidence used for analysis

\begin{tabular}{|c|c|c|c|c|c|}
\hline Article title & Publication & Year & Type & Focus of the study & $\begin{array}{l}\text { Level of } \\
\text { evidence }\end{array}$ \\
\hline \multicolumn{6}{|l|}{ Client with } \\
\hline Cerebral & & & & & \\
\hline Vascular & Online & & & & \\
\hline $\begin{array}{l}\text { Accident and } \\
\text { the interfaces } \\
\text { of nursing } \\
\text { care for } \\
\text { rehabilitation }\end{array}$ & $\begin{array}{l}\text { Brazilian } \\
\text { Journal of } \\
\text { Nursing }\end{array}$ & 2008 & $\begin{array}{l}\text { transversal } \\
\text { study }\end{array}$ & $\begin{array}{l}\text { To investigate clients affected by stroke, characterizing their sociodemographic } \\
\text { profile and the interfaces of nursing care for rehabilitation. }\end{array}$ & 3 \\
\hline $\begin{array}{l}\text { Nursing care } \\
\text { for the person } \\
\text { with stroke }\end{array}$ & $\begin{array}{l}\text { Cogitate } \\
\text { Nursing }\end{array}$ & 2008 & $\begin{array}{l}\text { Review } \\
\text { Study }\end{array}$ & $\begin{array}{l}\text { To analyze the knowledge described in the literature related to nursing care for } \\
\text { patients with pre-disposition and stroke, in order to consider the daily nursing } \\
\text { actions that contribute to the control of iatrogenic factors and rehabilitation of } \\
\text { the subject. }\end{array}$ & 2 \\
\hline $\begin{array}{l}\text { Nursing } \\
\text { actions in } \\
\text { pharmacological } \\
\text { therapy for } \\
\text { stroke: an } \\
\text { integrative } \\
\text { review }\end{array}$ & $\begin{array}{l}\text { Nursing } \\
\text { Journal UERJ }\end{array}$ & 2009 & $\begin{array}{l}\text { Review } \\
\text { Study }\end{array}$ & $\begin{array}{l}\text { Track productions on drug therapy for the treatment of risk factors for stroke } \\
\text { and discuss the actions of nurses in guiding this therapy. }\end{array}$ & 2 \\
\hline $\begin{array}{l}\text { Care of nursing } \\
\text { patients } \\
\text { with stroke: } \\
\text { integrative } \\
\text { review }\end{array}$ & $\begin{array}{l}\text { Online } \\
\text { Brazilian } \\
\text { Journal of } \\
\text { Nursing }\end{array}$ & 2010 & $\begin{array}{l}\text { Review } \\
\text { Study }\end{array}$ & $\begin{array}{l}\text { To analyze the available knowledge about the caregiver of nursing in the acute } \\
\text { phase of the AVE. }\end{array}$ & 2 \\
\hline $\begin{array}{l}\text { Nursing } \\
\text { interventions } \\
\text { in patients } \\
\text { with stroke: } \\
\text { an integrative } \\
\text { review }\end{array}$ & $\begin{array}{l}\text { Nursing } \\
\text { School } \\
\text { Magazine - } \\
\text { USP }\end{array}$ & 2011 & $\begin{array}{l}\text { Review } \\
\text { Study }\end{array}$ & $\begin{array}{l}\text { To analyze the knowledge about nursing interventions to patients hospitalized for } \\
\text { stroke. }\end{array}$ & 2 \\
\hline
\end{tabular}


Table I continued....

\begin{tabular}{|c|c|c|c|c|c|}
\hline Article title & Publication & Year & Type & Focus of the study & $\begin{array}{l}\text { Level of } \\
\text { evidence }\end{array}$ \\
\hline $\begin{array}{l}\text { Nursing } \\
\text { performance } \\
\text { in self-care and } \\
\text { rehabilitation } \\
\text { of patients } \\
\text { who suffered a } \\
\text { Stroke }\end{array}$ & $\begin{array}{l}\text { Brazilian } \\
\text { Journal of } \\
\text { Nursing }\end{array}$ & 2011 & $\begin{array}{l}\text { Experience } \\
\text { Report }\end{array}$ & $\begin{array}{l}\text { Report / share nursing care to the individual affected by stroke emphasizing } \\
\text { rehabilitation and self-care based on Orem. }\end{array}$ & 6 \\
\hline $\begin{array}{l}\text { Ischemic } \\
\text { stroke in young } \\
\text { patients }\end{array}$ & Collects SUS & 2012 & $\begin{array}{l}\text { Thesis of } \\
\text { Conclusion } \\
\text { of Course }\end{array}$ & $\begin{array}{l}\text { To understand the risk factors of a stroke in young patients, how the protocol } \\
\text { for the treatment of ischemic stroke works, what are the criteria for the use of } \\
\text { thrombolytic therapy in the acute phase of stroke and what actions, interventions } \\
\text { and nursing care in these situations. }\end{array}$ & 3 \\
\hline $\begin{array}{l}\text { Stroke care } \\
\text { line (CVA) in } \\
\text { the Emergency } \\
\text { and Emergency } \\
\text { Care Network }\end{array}$ & $\begin{array}{l}\text { Ministry of } \\
\text { Health of } \\
\text { Brazil }\end{array}$ & 2012 & Protocol & $\begin{array}{l}\text { Outline the care line to be followed in the care of the patient with stroke, aiming } \\
\text { at the integral care of the individual, glimpsing all his demands for health care. }\end{array}$ & 2 \\
\hline $\begin{array}{l}\text { Manual of } \\
\text { routines for } \\
\text { attention to } \\
\text { stroke }\end{array}$ & $\begin{array}{l}\text { Ministry of } \\
\text { Health of } \\
\text { Brazil }\end{array}$ & 2013 & Manual & $\begin{array}{l}\text { To present protocols, scales and guidelines to health professionals in the clinical } \\
\text { management of patients with stroke }\end{array}$ & 2 \\
\hline
\end{tabular}

\section{Discussion}

After analysis of the selected material, we chose to present the topic in accordance with the following topics: i) service Protocol stroke; II) Nursing care of the AVE the emergency phase; III) Nursing care in the prevention of risk factors for stroke and V) Nursing care in the rehabilitation process.

\section{Vascular accident care protocol brain}

In view of the social, economic and epidemiological impact of the AVE, it was necessary to create strategies that offered specific care guidelines for this condition. Therefore, in 2012 the AVE care line was established by Decree MS / GM No. 665 of April 12 of that year, as part of the Emergency Care Network and Emergency. ${ }^{12}$

This line aims to reduce morbidity and mortality in Brazil through comprehensive patient care by providing the best diagnostic and treatment strategies currently known. This assistance model follows the international guidelines that advocate the inclusion of interconnected health care points with predefined flows, represented by the actions of primary care, emergency/emergency services, stroke units, rehabilitation, outpatient care, and outpatient care. Social reintegration. ${ }^{13}$

In view of the above, the protocols, scales and guidelines for clinical management of patients affected by this event were presented in Brazil by the Manual of care routines for stroke. This manual confirms that the AVE is an emergency event and must be treated in a hospital setting 12 . Initially, we seek to identify the diagnoses and initiate drug therapy. The nurse, in turn, directs his actions to minimize the risks, sequels, deformities and iatrogenies of the disease. ${ }^{9}$

In addition, the manual lists service strategies, assessment scales of patients, inclusion and exclusion criteria for the use of thrombolytic, among other conduits for the themes: VE i or hemorrhagic as well as secondary prevention of these ${ }^{12}$ disorders.

\section{Nursing care in the emergency phase of stroke}

The AVE $\mathrm{i}$ aim of this study is characterized by disruption of blood flow in $\mathrm{m} u$ determined area of the brain. Due to the inability of neurological cells to store oxygen and glucose essential for its operation, the time of absence of blood supply is critical in the evolution of damage to the brain tissue. ${ }^{14}$ Consequently, the event requires emergency care since a faster screening, with evaluation and orientation of the patients in the acute phase of the pathology, allows the diagnosis and the most appropriate treatment within the effective therapeutic window. Furthermore, favors the provision of acute care, which aims to limit the progression of injury, promote neuroprotection and prevent recurrence..$^{15}$ The treatment protocols as the aforementioned manual, contain organized strategies for improving approach, routing and treatment of severe patients in the pre, inter and intra-hospital. The objectives of initial treatment in patients with acute stroke are: confirmation of the diagnosis, identification of the start time of the frame and its evolution and the degree of severity of the stroke. The assessments also includes the emergency stabilization of vital patient conditions, such as respiratory care, fluid and electrolyte balance, hemodynamic monitoring, dietary conditions, strict control of temperature and blood glucose and prevent will of deep vein thrombosis. ${ }^{12,13}$

It is in the emergency phase that the nurse initiates the client's evaluation, diagnoses the risk factors for iatrogenies, from the moment of the consultation until its hospital treatment. The main purpose of the evaluation and nursing actions is to prevent the consequences inherent to the disease and be alert, for the period of the patient in the hospital, which should be understood as a major difference $n$ the rehabilitation process it. ${ }^{9}$

The Systematization of Nursing Care can be based on neurological evaluation scales, with identification of motor and sensory deficits that give indications for the place of the AVE. These scales are useful to follow the course of the disease and to determine the prognosis, the preventive actions of iatrogenies, as well as rehabilitators. ${ }^{2}$

Since confirmation of the diagnosis of stroke only occurs after the 
performance of a CT scan, nursing performance can begin in the prehospital care, following the guideline of care recommended by the manual of routines and the care line in AVE12. In this sense, to detect the disease, the pre-hospital stroke scale can be applied to recognize the most frequent signs, such as: loss of muscle strength on one side of the body, radiating from the face to the upper and lower limbs; difficulty speaking and facial expression. ${ }^{13}$

At that moment, the nurse should initiate the clinical care: verification of the vital signs; Positioning straight head $\left(0^{\circ}\right.$, except in case of vomiting); Peripheral venous access in non-paretic upper limb; Oxygen administration by the nasal catheter or chewing (if pulse oximetry is $<95 \%$ ); Capillary glycemia check; determine the start time of the signs and symptoms reported by the patient or companion to establish the onset of time and the therapeutic window. ${ }^{13}$

From the diagnostic confirmation and taken the above care, nurses must apply the NIH scale (National Institutes of Health) by the doctor and start intravenous thrombolysis, when authorized by a physician, the therapeutic window is less than 4 hours and 30 minutes, for this the determination of the start of stroke must have happened within 3 hours. ${ }^{12,13}$ Thrombolytic therapy for suppression of stroke requires a number of care and determination criteria for its initiation, which are specified in the Manual of Routines and Care Line for Stroke MS.

Other studies confirm and complement some nursing care for the acute phase of stroke, such as: straight bed maintenance with raised grades for patient safety; maintenance of a quiet, poorly lit environment; intracranial pressure monitoring (ICP), with medical recommendation, and to avoid maneuvers that may elevate ICP, such as aspiration of the airways; assessment of neurological status by applying the Glasgow Coma Scale; attention to changes in heartbeat in the patient that may indicate risk of worsening of hypoxia beyond other possible respiratory irregularities; also verify hydration status, glycemic index and, above all, monitoring of vital signs, especially blood pressure. ${ }^{2,11}$

Although nursing practice is crucial in obrevida patient victim of stroke, and numerous are the interventions in emergency time and hospital stay, the function of this goes beyond medical treatment, extending the process of rehabilitation of the bodily functions of the individual, Lifestyle readjustment and guidance and support to both the person, the family and the caregiver shortly after discharge from hospital, in addition, care in the prevention of risk factors prove to be of fundamental importance in order to avoid the disease and, Mainly, its recurrence.

\section{The Nursing assistance in the prevention of risk factors for stroke}

As previously mentioned, stroke has high levels of morbidity and mortality, despite constant advances in diagnosis and therapeutics. This table provides indications that intervention in this process should occur in periods prior to this event. In Brazil, however, there is a policy aimed only at curing or at- tending the population already affected by the disease. The stroke, however, can be prevented and its approach is essentially the correction of risk factors, early diagnosis and the processing associated pathologies. ${ }^{16}$ It is agreed that the focus of prevention and control stroke is centered on reducing exposure to risk factors. ${ }^{17}$ These can be grouped into four categories: constitutional, represented by gender, age, race, and hereditary factors; Behavioral, which are smoking, diet, sedentary lifestyle, alcohol intake and contraceptive use; metabolic diseases or disorders associated whose main examples are high blood pressure (hypertension), heart disease, obesity, hyperlipidemia, diabetes; and social, economic and cultural as occupation, income, education, social class, work environment and other. ${ }^{18}$

In an attempt to reduce modifiable risk factors, patients should be instructed to make changes in lifestyle. This prevention is based on the following measures: Treatment H S; Control of Diabetes Mellitus; control of dyslipidemia and obesity; Smoking cessation; abstaining from alcohol and drugs and encouraging physical activity. ${ }^{19}$

The Family Health Strategy (FHS) team that accompanies the users and associated risk factors promotes nursing diagnosis, interaction with patients through care models, and prevention and recognition of risks. At this level of assistance the work of professionals in the control of hypertension and smoking, in addition to the reduction of fatalities due to the rapid and specialized treatment, associated with the increasing advancement in clinical managements, is related to the decline in deaths from VE. ${ }^{9}$

The main action of nurses about the risk factors is patient education. Process that helps you learns and incorporate healthy habits that will become part of everyday life. The change in lifestyle afforded by that nursing professional activity contributes in reducing the incidence of stroke by preventing their $r$ bait factors. Besides being an efficient means to save resources now used in the treatment of patients or lost productivity. ${ }^{16}$

\section{Nursing care in the rehabilitation process}

Many studies have shown also the nursing care provided for rehabilitation of people with stroke, and also that there are many guidelines and essential care in the prevention of risk factors. ${ }^{2,9,20,21}$ Dysfunctions generated by the disease are very common, such as depression, anxiety, insomnia, sexual dysfunction, motor dysfunction, sensory, cognitive, among other problems. The nursing interventions become, accordingly, the treatment tool and improved clinical outcomes and reduced dry them, present in $90 \%$ of cases. ${ }^{21}$

Interventions in postural control, such as bed positioning, change of decubitus, limb lengthening, respecting the anatomical positioning and using cushions, pillows and cushions, are activities performed by nursing in the self care and rehabilitation of the individual with stroke. Such precautions are made necessary because the neurovascular disease causes power changes, sensitivity and control ${ }^{20}$ motors. Activities related to the range of movements, sensory stimulation and gait training are performed and strengthened through health education. Nursing along the interdisciplinary team can make guidelines on the prevention of falls and maintaining balance within their own homes. ${ }^{20}$ Researchers confirm that in addition to motor rehabilitation, functional rehabilitation helps patients integrate daily life activities to the technical skills to return to carry out such activities with security. ${ }^{9.21}$

Significant care is also shown after discharge from the patient so that the process of reestablishing the patient's functions can be carried out with the same efficiency by the caregiver or family member when he is at home, and nursing is responsible for guiding therapeutic actions, occupational, physical activity and nutrition to the question, $\mathrm{s}$ important for customer recovery. ${ }^{9}$

\section{Conclusion}

In view of the foregoing, it is clear that stroke is a disease that requires prevention and global treatment and that the recognition of 
signs and symptoms should occur as soon as possible, so that clinical treatment can be initiated within the time of 4.5 hours, demonstrating that the onset of the acute care requires an interdisciplinary approach, emphasizing the importance of nursing in identification of the signs and symptoms from pre-hospital care the application of emergency care. Thus, the rapid performance of the team and an adequately performed inter-hospital nursing care are determinant for a better prognosis of the disease, since the earlier the clinical treatment is started, and the better the chances of patient survival with stroke and lower the occurrence of sequelae.

This integrative review possible also demonstrate the importance that nursing has, not only in the emergency moment because after stabilization of the patient's condition, interventions are needed to contribute to the rehabilitation of it, and nursing as a social character profession, Also acts in the orientation to the post-discharge care, both for the patient and his caregiver, so that the patient can reestablish his or her organic functions.

It is worth noting, the need for health education for the population to learn to recognize the signs and symptoms $d$ the stroke so that the search for health services happen urgently and for this, the nurse can act in the prevention of risk factors in order to prevent the occurrence or recurrence even ischemic stroke.

It is hoped that the present study will subsidize researchers' interest in deepening the more specific approach to stroke, given the few studies found to support this work, given its importance as a growing disease in morbidity and predominantly among types of stroke. Just as it is necessary to raise the interest in studies focusing on the nursing role in this context, stressing the importance of professional intervention in interdisciplinary team during and after the acute phase of the disease.

\section{Acknowledgements}

None.

\section{Conflict of interest}

The author declares that there is no conflict of interest.

\section{References}

1. Hinkle JL, Guanci MM. Acute ischemic stroke review. $J$ Neuroscience Nurs. 2007;39(5):285-93.

2. Bianchini SM, Galvão CM, Arcuri EAM. Nursing care for patients with stroke: an integrative review. Online Braz J Nurs. 2010;9(2).

3. Brazil. Ministry of Health. Clinical prevention of cardiovascular, cerebrovascular and renal diseases.

4. Pereira ABCNG, Alvarenga $\mathrm{H}$, Pereira Junior RB, et al. Prevalence of stroke in the elderly in the Municipality of Vassouras, Rio de Janeiro, Brazil, through the data collection of the Family Health program. Cad Saúde Pública. 2009;25(9):1929-1936.

5. DATASUS. Information Technology at the SUS Service. Brazil mortality - deaths per household per year of death according ICD-10 group in 2010. Ministry of Health, 2010.

6. World Health Organization (WHO). The atlas of heart disease and stroke. Geneva.

7. Abramczuk B, Villela E. The fight against stroke in Brazil. ComCiência,Campi. 2009;(109).

8. Brunner LS, Smeltzer SCS, Brunner \& Suddarth. Medical-Surgical Nursing Treaty. 12th ed. Rio de Ja Neiro: Guanabara Koogan; 2012.

9. Gomes RG, Senna M. Nursing care to the person with Stroke. Cogit are Enferm. 2008;13(2):220-226.

10. Maniva SJCDF, Freitas CHA. Nursing care in illness for stroke: integrative review of Brazilian literature. Electronic Journal of Nursing. 2012;14(3):679-89.

11. Osorio GTF. Ischemic Stroke in young patients. Porto Alegre (RS): Brazil; 2012.

12. Ministry of Health. Department of Health Care. Department of Specialized Care. Manual routines for attention to AVC/Ministry of Health Brasilia. Ministry of Health, 2013.

13. Ministry of Health. Stroke Care Line at (AVC) on the network Attention to Emergencies and Emergencies.

14. JL Braga, Alvarenga RMP, Mores Grandchildren JBM. Stroke. Rev Bras Med. 2003;60(3):88-96.

15. Pimentel MH, Pereira OR. Today Pharmacy, Tomorrow Drugs. School of Health Sciences, Polytechnic Institute of Bragança, Portugal, 2012.

16. Azevedo RVM, Moretão DIC, Moretão VJ. Stroke prevention in patients with heart disease. Revist the Intersection. 2008;1(2):82-90.

17. Silva LD, MD Henry, Schutz nursing actions in the pharmacological therapy for stroke: an integrative review. UERJ Nursing Journal. 2009; 17(3):423-429.

18. CJV Euzébio, Rabinovich. Understanding family caregivers of patients with sequelae of cerebrovascular accident. Themes of Psychology .2006;14(1):63-79.

19. Ribeiro JM .Secondary prevention of stroke. Rev Bras Hypertension. 2003;10(2):142-144.

20. LessmannI JC, F Tale, Greice R, et al. Nursing activities in self-care and rehabilitation of patients who suffered Vascular Brain Accident. Rev Bra s Enferm. 2011;64(1):198-202.

21. Cavalcante TF, Moreira RP, Guedes NG, et al. Nursing interventions to patients with stroke: an integrative literature review. Rev Esc Enferm USP. 2011;45(6):1495-500. 